Revista IBERC

v. 4, n. 1, p. 52-64, jan./abr. 2021

www.responsabilidadecivil.org/revista-iberc

DOI: https://doi.org/10.37963/iberc.v3i2.153

\title{
LUCRO DA INTERVENÇÃO E O USO EXCLUSIVO DO IMÓVEL DO CASAL APÓS A SEPARAÇÃO DE FATO
}

\author{
PROFIT OF INTERVENTION AND EXCLUSIVE USE OF THE COUPLE'S PROPERTY AFTER \\ SEPARATION IN FACT
}

Leandro Reinaldo da Cunha ${ }^{i}$

RESUMO: Nos dias atuais a realidade das pessoas se mostra muito diversa daquela existente outrora, mormente no que tange ao início e ao término das relações afetivas, sendo que o casamento e a união estável são temas que se encontram no centro de tal discussão. Ante a essa nova cena social estabelecida hodiernamente, aquela indissolubilidade que antes vigia com relação aos casamentos não mais se faz presente, sendo certo que o término dos casamentos (e mais recentemente das uniões estáveis) se dá, ao menos de fato, com o simples desejo de um dos indivíduos, ante o seu afastamento do lar conjugal com o intuito de pôr termo àquela relação. Inserida nesse contexto se verifica uma situação cada vez mais recorrente em que um dos cônjuges/companheiros acaba por exercer de forma exclusiva a posse direta sobre os bens (sejam eles móveis ou imóveis) do casal, o que suscita a discussão sobre os direitos do outro relativos a tal uso. De tal sorte o presente trabalho tem por escopo a análise quanto a existência ou não de uma obrigação de restituir em tais casos, bem como os fundamentos que o alicerçariam, se lastreado no dever de indenizar ante a um dano causado ou se oriundo do lucro da intervenção.

Palavras-chave: Dever de restituir. Enriquecimento sem causa. Lucro da intervenção. Separação de fato.

\begin{abstract}
Nowadays the reality of people is very different from the one that existed before, especially with regard to the beginning and the end of affective relationships, with marriage and common-law marriage being themes that are at the center of such discussion. Faced with this new social scene established, that indissolubility that previously prevails in relation to marriages is no longer present, being certain that the termination of marriages (and more recently of common-law marriage) occurs, at least in fact, with the simple desire of one, with their departure from the marital home with the aim of ending that relationship. In this context, there is an increasingly recurrent situation in which one of the spouses / partners ends up exercising exclusive ownership of the couple's property (whether movable or immovable), which raises the discussion about the rights of the other relating to such use. In such a way the present work has as scope the analysis as to the existence or not of a obligation to return in such cases, as well as the foundations that would support it, if supported by the obligation to indemnify in the face of damage caused or if it comes from profit of the intervention.
\end{abstract}

Keywords: Obligation to return. Unjustified enrichment. Profit of the intervention. Separation in fact.

SUMÁRIO: 1 Introdução. 2 Fim do casamento/união estável e o patrimônio do casal. 3 Consequências do uso exclusivo do bem comum após o fim do casamento ou união estável. 4 Utilização exclusiva de bem comum e o lucro da intervenção. 5 Conclusão. Referências.

\footnotetext{
i Professor Titular-Livre de Direito Civil da Universidade Federal da Bahia (graduação, mestrado e doutorado). Pós doutor e Doutor em Direito pela Pontifícia Universidade Católica de São Paulo - PUC/SP e Mestre em Direito pela Universidade Metropolitana de Santos - UNIMES. Pesquisador Científico. Investigador da Rede Visões Cruzadas sobre a Contemporaneidade (Rede VCC). Associado Titular do Instituto Brasileiro de Estudos de Responsabilidade Civil (IBERC). Líder do grupo de pesquisa "Direito e Sexualidade". https://orcid.org/0000-0003-2062-2184. leandro.reinaldo@ufba.br
} 


\section{INTRODUÇÃO}

A atual realidade da sociedade revela que os laços matrimoniais já não são mais tão afeitos à ideia da indissolubilidade que a cerimônia do casamento religioso ainda gosta de exaltar. A construção socialmente consolidada de que "o que Deus uniu o homem não separa" encontrase bastante fragilizada com a colocação da vontade do indivíduo no centro dessa questão, o que também se constata nas uniões estáveis.

O matrimônio que outrora, nos termos da lei, não poderia ser objeto de dissolução (resquício inequívoco da força da Igreja no Estado mesmo após a separação de ambos) passou por inúmeras fases e atualmente pode ter seu termo de forma simples, lastreado exclusivamente no elemento volitivo de um dos cônjuges, e, por vezes, até mesmo sem a chancela do Poder Judiciário, nas hipóteses em que a lei autoriza a dissolução na modalidade extrajudicial.

O fim do casamento ou da união estável são apenas o pano de fundo para a discussão que se propõe no presente texto, sendo certo que aqui não nos ateremos de forma pontual às formas de suas constituições, direitos e deveres que os regem, regimes de bens, tampouco as modalidades em que se podem dar suas dissoluções.

A questão fulcral do presente escrito está em um dos desdobramentos do fim da vida em comum daqueles que, através do casamento ou da união estável, viviam uma comunhão. Sendo mais específico, nos ateremos a uma das consequências patrimoniais de tal ruptura.

Um dos aspectos tendentes a gerar mais controvérsias em sede de dissolução de relacionamentos incide na questão da partilha patrimonial, fato este que tem relação direta, obviamente, com o regime de bens estabelecido naquele casamento ou união estável. Nessa senda é ainda importante consignar que já de longa data se tem consolidado o entendimento de que a dissolução do casamento pode se dar sem que se realize a partilha dos bens do casal, a qual pode ser relegada para um momento posterior, efetivando-se pelas vias próprias. Há ainda que se ponderar sobre os inúmeros casos em que o relacionamento encontra o seu termo de fato sem que isso venha a ser juridicamente formalizado, situação em que aspectos patrimoniais também poderão ensejar certa celeuma.

O elemento nuclear que nos move na presente discussão reside exatamente naquelas situações em que o casamento ou a união estável encontrou o seu fim e, havendo bens a serem divididos, tal partilha não se efetiva de forma pronta, fazendo com que um dos cônjuges ou conviventes venha a exercer com exclusividade a posse sobre bens pertencentes a ambos. Nessa situação compete àquele que está privado do exercício da posse direta do bem alguma compensação financeira? Caso afirmativa a resposta para a questão anterior, qual seria a natureza dessa obrigação de restituir?

Partindo dessa introdução, o objetivo é discutir se a presente situação se insere em um contexto de manutenção da mancomunhão oriunda do casamento ou união estável, ou se tratase de uma figura de condomínio geral em que cabe pretensão indenizatória, ou se a questão há de ser resolvida segundo os parâmetros do enriquecimento sem causa ensejando a obrigação de 
restituir o lucro da intervenção, hipótese esta que, antecipadamente, já afirmamos ser a mais adequada, como ficará demonstrado.

\section{FIM DO CASAMENTO/UNIÃO ESTÁVEL E O PATRIMÔNIO DO CASAL}

Sob o viés de um direito de família amplamente patrimonialista que nos acompanha há séculos, uma das grandes preocupações das codificações civis sempre foi a relação entre os casados e o patrimônio, sendo que mais recentemente (segundo uma perspectiva histórica) tal questão também passou a abranger as uniões estáveis.

Contudo em linhas bastante gerais e panorâmicas temos que atualmente o que fixa a relação dos cônjuges na esfera patrimonial é o regime de bens, o qual é eleito pelas partes, imposto pela lei ou fixado de forma subsidiária quando não é feita uma escolha, sendo que o mesmo se aplica aos companheiros. Corolário dessa visão que tem o patrimônio no centro das questões matrimoniais/convivenciais está a indissociabilidade do casamento/união estável de um regime de bens.

Como asseverado alhures a questão a ser trazida aqui não é especificamente sobre os regimes de bens e a forma como incidem sobre o patrimônio individual ou comum daquelas pessoas, sendo que nos ateremos a uma situação bastante simples. O ponto elementar que move o presente texto está na compreensão acerca da propriedade e posse dos bens comuns do casal após a separação de fato.

A questão da propriedade, em verdade, para o presente estudo é entendida de forma muito simples. Baseado nos parâmetros relativos ao momento da aquisição do bem e ao regime de bens que imperava naquela relação, haverá a aferição quanto a quem é o proprietário do bem e aqui apenas nos importa hipóteses em que se tenha a caracterização de copropriedade.

O outro elemento preponderante para a discussão que aqui se coloca, dessa vez relacionado à posse, está no fato de apenas um dos cônjuges ou companheiros exercê-la de forma direta sobre o bem comum, beneficiando-se exclusivamente dele. Reitera-se que a natureza do bem no presente caso, se móvel ou imóvel, é elemento de menor importância, ainda que seja evidente que os questionamentos, na prática, surjam mais quando diante de bens de raiz ou móveis de valor elevado.

Um dos pontos mais relevantes para a apreciação da presente situação recai sobre a ideia de que poder-se-ia laborar com o conceito de extensão da mancomunhão decorrente do casamento/união estável, baseado na perspectiva de que na constância do casamento o patrimônio é comum do casal (REsp n 3.710/RS, julgado em 21/06/1995).

A mancomunhão (comunhão de mãos fechadas) revela-se como uma consequência do casamento ou união estável, mais especificamente do regime de bens, quanto ao patrimônio comum do casal, indo além da simples ideia de condomínio, vez que na constância do 
relacionamento ambos são proprietários do todo, sem qualquer fracionamento ideal ${ }^{1}$. Assim, cônjuges ou companheiros seriam, na constância do casamento/união estável, proprietários dos bens comuns de forma plena, sem que houvesse uma parcela ideal que seria destinada a cada deles. Ou seja, seriam donos do todo em conjunto.

A perspectiva da extensão da mancomunhão para depois da resolução fática do casamento/união estável alicerça-se, de forma singela, na figura de que apenas o término formal do casamento teria o condão de pôr fim ao vínculo decorrente do regime de bens que une cônjuges ou companheiros, lastreado no disposto no art. 1.576 do Código Civil que assevera expressamente, entre outras coisas, que a separação judicial põe termo ao regime de bens.

Contudo nesse momento se faz imprescindível tecer algumas considerações acerca da separação de fato, a qual atualmente reveste-se de uma normalidade que não apresentava outrora, revelando-se como a consequência natural do término do afeto conjugal, isenta da reprovação jurídica que sustentava a concepção de indissolubilidade do casamento que reinava noutros tempos ${ }^{2}$.

Já se mostra bastante consolidada, tanto na doutrina quanto na jurisprudência, a possibilidade de advirem efeitos jurídicos da separação de fato, calcado na teoria da primazia da realidade ${ }^{3}$, mormente quando demonstrado de forma inconteste o intuito de encerrar 0 relacionamento. Constatado tal intento uma das consequências essenciais será a cessação dos efeitos do regime de bens ${ }^{4}$, haja vista que com tal ruptura a comunhão de vidas (que não se manifesta na mera convivência more uxório) primordial para o regime de bens já não mais existe 5 .

Por lógica, se há o término da comunhão de vidas ante a separação de fato, findo estará o regime de bens e, consequentemente, o estado de mancomunhão, sendo que a indivisão patrimonial característica dos casamentos e uniões estáveis com regimes de bens que as prevê também se extingue, passando os cônjuges/companheiros a figurarem como cotitulares de um bem comum ${ }^{6}$.

Em assim sendo não nos parece adequada uma visão tendente a discutir a manutenção de qualquer sorte de comunhão baseada no casamento após o seu encerramento de fato, havendo de prevalecer o entendimento de que todos os efeitos que decorreriam da separação judicial podem ser atingidos com a separação de fato, vez que tal consideração atende plenamente ao interesse daqueles que estão rompendo tal relacionamento ${ }^{7}$.

O que se sustenta é que seria inadmissível, segundo os parâmetros atualmente vigentes,

\footnotetext{
${ }^{1}$ GOMES, Josiane Araújo. Temas contemporâneos de direito das famílias. Volume 3. São Paulo: Editora Pillares, 2018. p. 346.

2 LÔBO, Paulo. Famílias. 2. ed., São Paulo: Saraiva, 2009. p. 132.

${ }^{3}$ FARIAS, Cristiano Chaves de. ROSENVALD, Nelson. Curso de direito civil: Famílias. 7. ed., São Paulo: Atlas, 2015. p. 362.

4 TEPEDINO, Gustavo; TEIXEIRA, Ana Carolina Brochado. Direito de Família. Rio de Janeiro: Forense, 2020. p. 143.

${ }^{5}$ Enunciado 02 do IBDFAM - A separação de fato põe fim ao regime de bens e importa extinção dos deveres entre cônjuges e entre companheiros.

${ }^{6}$ GOMES, Josiane Araújo. Temas contemporâneos de direito das famílias. Volume 3. São Paulo: Editora Pillares, 2018. p. 346.

${ }^{7}$ FARIAS, Cristiano Chaves de. ROSENVALD, Nelson. Curso de direito civil: Famílias. 7. ed., São Paulo: Atlas, 2015. p. 364.
} 
se conceber a perspectiva da prevalência da mancomunhão quando já não mais existe qualquer comunhão entre aqueles cônjuges/companheiros ante a separação de fato ocorrida. Ao nosso sentir qualquer entendimento diverso revelaria a imposição de uma ideia que não se sustenta logicamente, considerando que o elemento que deu origem à mancomunhão (regime de bens) deixou de existir com o término fático do relacionamento.

$O$ outro entendimento que se tem adotado em sede de uso exclusivo de bem comum do casal após a separação de fato é a existência de uma figura de condomínio geral, a qual se mostra inegável, em um primeiro momento, vez que a coisa é objeto de direito real de propriedade pertencente a mais do que uma pessoa. Porém, em que pese tal fato, não se pode olvidar que trata-se de um condomínio que emana da lei, resultante da escolha do regime de bens daquele casamento ou união estável e que, embora tenha origem em um elemento volitivo, não se vincula às regras da comunhão espontânea no que se refere à sua extinção8 .

Evidencia-se, portanto, que a presente questão assenta-se sobre uma modalidade de condomínio bastante específica, que nasceu de uma relação matrimonial ou convivencial e que, quando essa vem a findar-se, se mostra ordinário o entendimento de que cada qual tem interesse em sua parte do bem comum. Tanto é assim que a própria legislação ao tratar da dissolução do casamento tem como consequência natural, prevista no art. 1.575 do Código Civil, a partilha do patrimônio comum do casal, sendo de se concluir que o destino do condomínio originado do casamento/união estável rume para sua extinção juntamente com o relacionamento.

Nesse contexto o excepcional seria que o interesse daqueles que se separaram de fato fosse a perpetuação de um condomínio originário não exatamente de uma vontade destinada para esse fim, mas decorrente, de forma reflexa, daquele casamento/união estável que acaba de ruir.

Nas modalidades de condomínio voluntário, decorrentes de um negócio jurídico, por exemplo, em que não há necessariamente um fato que seja caracterizador do fim da affectio que motivou as partes a estabelecerem o condomínio, é imprescindível que o desejo de findar a copropriedade seja manifestada de forma expressa. De outro lado, porém, nos casos em que o condomínio nasce do casamento/união estável a ruptura desse relacionamento é um marco muito sólido e característico que permite presumir, ainda que iuris tantum, o interesse de dissolução do condomínio, sendo que é essa a consequência natural e até mesmo prevista expressamente na lei.

Ainda nessa seara não se pode olvidar que nos condomínios gerais a perspectiva prevalente é que todos os condôminos possam utilizar do bem comum, o que não parece ser aplicável, na prática, a uma hipótese em que tal condomínio nasceu de um casamento/união estável. É patente que o fim do relacionamento fará com que, na grande maioria das vezes, haja a utilização exclusiva do bem por um dos coproprietários, com a exclusão do exercício da posse de maneira simultânea, sendo certo que a tentativa de impor a aplicação dos preceitos inerentes ao condomínio geral revela-se inviável.

$\mathrm{O}$ que se quer evidenciar aqui é que as peculiaridades inerentes à origem de tal

${ }^{8}$ GOMES, Orlando. Direitos Reais. 19. ed. rev. e atual. Rio de Janeiro: Forense, 2007. p. $239-241$. 
condomínio não permitem que se faça uma apreciação usual, sendo imprescindível uma compreensão adequada da situação que se apresenta e que se mostra absolutamente distinta da figura tradicional de um condomínio, o que se faz preponderante para a discussão central que se busca estabelecer.

\section{CONSEQUÊNCIAS DO USO EXCLUSIVO DO BEM COMUM APÓS O FIM DO CASAMENTO OU UNIÃO ESTÁVEL}

A utilização exclusiva do bem comum por um dos cônjuges/companheiros após o término do casamento/união estável é situação de extrema relevância e de ocorrência reiterada na sociedade, até mesmo tendo sido elemento ensejador, por exemplo, de alteração legislativa com a inserção da figura da usucapião familiar (Art. 1.240-A do Código Civil).

O fato inconteste é que o uso exclusivo pode se originar de situações distintas ou então se apresentar de formas peculiares. Qualquer que seja a hipótese prontamente asseveramos que entendemos totalmente inadmissível a perspectiva de que em caso se estaria diante de uma anuência tácita para que o outro cônjuge/companheiro permaneça sozinho na posse do bem comum, em uma presunção de comodato por prazo indeterminado, nos termos trazidos pelo Superior Tribunal de Justiça (STJ) outrora (REsp 178.130/RS, Quarta Turma, DJ 17/06/2002), mormente ante a ausência de qualquer elemento que possa revelar o intuito da prática de ato gracioso.

Afastada tal possibilidade, a posse exclusiva do bem pode ser situação precedida apenas da separação de fato do casal (a), ou da separação judicial mas não do divórcio/dissolução da união estável (b), ou houve o divórcio/dissolução da união estável mas não ocorreu ainda a partilha por ter sido relegada a um momento posterior (c), ou se deu o divórcio /dissolução da união estável e determinou-se a partilha, mas essa ainda não se efetivou (d) ou, em última hipótese, já houve também o pedido judicial para a dissolução do condomínio sem que tenha sido efetivado até o momento (e).

O Superior Tribunal de Justiça (STJ) quando instado a manifestar-se sobre o tema tem levado em consideração tal questão. No REsp 1.250.362/RS, de relatoria do Min. Raul Araújo, em que se apontou divergência jurisprudencial da decisão de $2^{a}$ instância com o REsp 983.450/RS, e que foi julgado pela $2^{a}$ Seção por maioria, entendeu-se pela indenização ante ao uso exclusivo de imóvel comum ainda não partilhado, pontuando que tal possibilidade haveria que atender a determinadas circunstâncias.

Em seu voto o Min. Raul Araújo colaciona decisões proferidas anteriormente determinando a possibilidade indenização, mesmo antes da formalização da partilha, pelo equivalente à metade do valor do aluguel do bem, desde a citação, pelas regras do condomínio (EResp 130.605/DF, REsp 178.130/RS, REsp 436.935/RS), ressaltando também a existência de julgados impondo tal direito apenas depois da partilha (REsp 1.470.906/SP, AgRg no REsp 1.278.071/MG, EDcl no Ag 1.424.011/BA, AgRg no Ag 1.212.247/SP).

O entendimento considerado por ele, ao fim e ao cabo, foi de que "a pendência da 
efetivação da partilha de bem comum não representa automático empecilho ao pagamento de indenização pelo seu uso exclusivo, desde que a parte que toca a cada um dos ex-cônjuges tenha sido definida por qualquer meio inequívoco, sempre suscetível de revisão judicial e fiscalização pelo Ministério Público; e b) o indigitado direito à indenização também não é automático, sujeitando-se às peculiaridades do caso concreto sopesadas pelas instâncias de origem", considerando que o dever de pagar os aluguéis terá como termo inicial o momento em que se teve o inequívoco conhecimento da pretensão.

Em voto vencido o Min. Ricardo Villas Bôas Cueva reconhece a existência de divergência entre precedentes e pondera que inexiste no "ordenamento pátrio norma expressa regulamentando o direito do cônjuge que deixa o lar de ser indenizado pela impossibilidade de usar acervo patrimonial ainda pendente de efetiva divisão", não havendo previsão para indenização ante mera ruptura do casamento, e, com isso, posiciona-se pelo ressarcimento em tal situação apenas após decretada a separação ou divórcio e efetuada a partilha. Consigna ainda, como trouxe a Min. Maria Isabel Gallotti em seu voto, que a questão seria mais vinculada a um enriquecimento sem causa decorrente do fato de impedir, injustamente, que o outro usufrua de imóvel comum, conduta essa que se reputa ilícita, entendendo ele se tratar de figura de abuso de direito e não de enriquecimento sem causa como propugna a Ministra.

Em seu voto a Ministra Maria Isabel Gallotti ainda traz que, ante a vedação do enriquecimento sem causa, "se apenas um dos ex-cônjuges utiliza o bem de forma exclusiva, impedindo de forma concreta ou prática o usufruto comum do bem, independentemente de estar submetido ao estado de mancomunhão ou de condomínio, em face de já se ter operado a partilha ou não, surge o direito do outro de ser ressarcido" nos termos do art. 884 do Código Civil, lembrando ainda jurisprudência dominante no sentido de que a separação de fato faz cessar a presunção da aquisição de patrimônio ser decorrente de esforço comum, e que atrelar o direito a eventual indenização à partilha estimularia o detentor da posse a retardá-la.

Em seu voto neste mesmo caso a Ministra Nancy Andrighi pondera que nas hipóteses em que se deu a separação de fato ou o divórcio "de regra, o incômodo decorrente da ruptura conjugal impede uma fruição conjunta de um bem, notadamente se utilizado como residência ou local de trabalho por um dos ex-cônjuges" existindo um "sentimento de repulsa pela fruição concomitante de imóvel, ou mesmo bem móvel, o que gera evidente desequilíbrio entre aquele que monopoliza o patrimônio para si e o outro que nada usufrui", o que não ensejaria um abuso de direito mas revela situação a gerar um desequilíbrio patrimonial entre as partes, concluindo que a questão assenta-se na discussão quanto a posse existente sobre o patrimônio comum "para apontar a necessidade de quem faz uso exclusivo deste, indenizar, proporcionalmente, o excônjuge alijado da fruição".

Após a decisão proferida no REsp 1.250.362/RS, a Min. Nancy Andrighi, em seu voto no REsp 1.275.271/SP, fixou parâmetros para que haja compensação em favor daquele que não tem o bem consigo, determinando que o direito à indenização equivalente a 50\% (cinquenta por cento) do valor do aluguel (apurado em perícia) haveria de ser pago ao cônjuge que ficou sem a posse do bem, com termo inicial após a citação, considerando a incontrovérsia do divórcio com a 
determinação de partilha posterior pelas vias próprias. Assim, tendo havido a fixação da propriedade de metade do imóvel para cada um, bem como ação de extinção de condomínio julgada procedente, demonstrando a vontade expressa de dissolução do condomínio, haveria de aplicar-se o disposto no art. 1.319 do Código Civil, com a necessidade de acolhida da pretensão de indenização sob o risco de "indiscutível e inadmissível enriquecimento ilícito".

Preponderante se pontuar que em sede de condomínio há a presunção de que as partes dos condôminos são iguais, conforme preconiza o parágrafo único do art. 1.315 do Código Civil, ponto que se mostra relevante para os desdobramentos trazidos para a aplicação do dever de indenizar baseado nos danos causados por um condômino ao outro.

Em que pese a discussão estabelecida no Superior Tribunal de Justiça (STJ) sobre o uso exclusivo do bem comum, ousamos discordar das soluções estabelecidas, por entender que no presente caso não se mostra cabível a perspectiva da ausência do dever de indenizar ante a mancomunhão oriunda do casamento ou face a danos causados ao condômino. A nós se mostra adequada aqui a aplicação dos ditames da obrigação de restituir o lucro da intervenção.

\section{UTILIZAÇÃO EXCLUSIVA DE BEM COMUM E O LUCRO DA INTERVENÇÃO}

Ainda que tema historicamente recente nas discussões nacionais sobre a vedação legal do enriquecimento sem causa, a figura do lucro da intervenção começa a ganhar contornos de relevância. Apesar de sua aparente novidade o lucro da intervenção é objeto do Enunciado $n^{\circ} 620$ da VIII Jornada de Direito Civil do Centro de Estudos Judiciários do Conselho da Justiça Federal.

Enunciado 620.

"A obrigação de restituir o lucro da intervenção, entendido como a vantagem patrimonial auferida a partir da exploração não autorizada de bem ou direito alheio, fundamenta-se na vedação do enriquecimento sem causa".

O lucro da intervenção há de ser entendido como aquelas "situações nas quais uma determinada pessoa aufere vantagem patrimonial a partir da exploração não autorizada de bens ou direitos alheios"9, de sorte que aquele que obtém benefícios haverá de restituir tais ganhos a quem de direito. Ou, como sinteticamente define Carlos Nelson Konder, "é qualquer vantagem patrimonial obtida indevidamente com base em direito alheio", sendo que "qualquer ato de exploração ou aproveitamento, intencional ou não, de forma não autorizada pode, em alguma medida, ser reconduzido à figura do lucro da intervenção" 10 .

Importante consignar-se aqui o entendimento de que ao se falar em ganhos ou vantagens patrimoniais auferidas não se pensa apenas em um aumento de patrimônio ante a utilização do bem, mas também no que o indivíduo deixou de dispender ou gastar em decorrência de sua intervenção ou utilização sobre bem ou direito que não the pertence. Aqui é possível se

\footnotetext{
${ }^{9}$ SILVA, Rodrigo da Guia. Enriquecimento sem causa: as obrigações restitutórias no direito civil. São Paulo: Thomson Reuters, 2018, p. 300.

10 KONDER, Carlos Nelson. Dificuldades de uma abordagem unitária do lucro da intervenção. Revista de Direito Civil Contemporâneo, v. 13, n. 4, p. 231-248, out./dez. 2017. p. 233.
} 
apreciar a questão segundo enriquecimento real, que é calculado segundo o valor de mercado da vantagem obtida, ou com base no enriquecimento patrimonial considerado segundo o impacto constatado no patrimônio do beneficiado face a diferença entre o seu patrimônio após o benefício indevido e a situação em hipótese se se encontraria se não houvesse se gozado de tal enriquecimento ${ }^{11}$.

Assim, o enriquecimento do interventor pode verificar-se, portanto, tanto por meio de um incremento do seu ativo, como de uma diminuição do seu passivo, mas também de uma poupança de despesa ${ }^{12}$.

Como a figura do lucro da intervenção se insere nos limites da perspectiva do enriquecimento sem causa é preponderante não se olvidar que nessa seara se mostra irrelevante tecer quaisquer ponderações acerca de culpa ou má-fé daquele que aproveitou-se do bem alheio para a sua caracterização, tendo relevância apenas para considerações acerca do montante a ser restituído ${ }^{13}$, exatamente por não se tratar de uma figura vinculada à responsabilidade civil ou à existência de um dano em sua concepção clássica, vez que pretensão indenizatória e de restituição do lucro da intervenção mostram-se como coisas diferentes entre si $^{14}$.

Estabelecidas as premissas básicas sobre o lucro da intervenção fica cristalina a sua perfeita adequação nos casos de utilização exclusiva de bem pertencente a ambos os cônjuges/companheiros após a ruptura do relacionamento afetivo.

Partindo-se do pressuposto assumido até o presente momento de que para fins patrimoniais a dissolução do vínculo se dá com a separação de fato, tem-se que desde então aquele que exerce exclusivamente a posse sobre o bem comum do casal está utilizando-se, ao menos em parte, de bem que não lhe pertence sem qualquer autorização para tanto.

Evidentemente que para os partidários da tese da mancomunhão as considerações a seguir trazidas apenas tem aplicação após o divórcio, sem que isso afaste a incidência da figura do lucro da intervenção.

O que nos parece bastante evidente é que a situação em tela não admite qualquer discussão relativa ao dano causado pelo condômino ao outro (art. 1.319 do Código Civil), por entender que no caso não se trata de uma questão de responsabilidade civil, vez que não se verifica a presença da prática de um dano em si, mas sim um enriquecimento sem causa, cabendo a incidência dos parâmetros gerais disposto no art. 884 da lei material.

No nosso sentir se mostra desnecessária qualquer tipo de discussão relativa às hipóteses em que ocorra a utilização exclusiva de bem comum que ultrapassem a aferição acerca de quem é o proprietário do bem (a), quem exerce a posse direta (b) e se tal exercício é ou não

\footnotetext{
${ }^{11}$ KONDER, Carlos Nelson. Dificuldades de uma abordagem unitária do lucro da intervenção. Revista de Direito Civil Contemporâneo, v. 13, n. 4, p. 231-248, out./dez. 2017. p. 242.

12 SCHREIBER, Anderson. SILVA, Rodrigo da Guia. Aspectos relevantes para a sistematização do lucro da intervenção no direito brasileiro. Pensar, Fortaleza, v. 23, n. 4, p. 1-15, out./dez. 2018, p. 09.

${ }^{13}$ FAJNGOLD, Leonardo; SALGADO, Bernardo; GUERRCHON, Dan. Lucro da intervenção: a disciplina e os julgamentos pioneiros no Superior Tribunal de Justiça. Revista Brasileira de Direito Civil - RBDCivil, Belo Horizonte, v. 21, jul./set. 2019, p. 177.

${ }^{14}$ SILVA, Rodrigo da Guia. Enriquecimento sem causa: as obrigações restitutórias no direito civil. São Paulo: Thomson Reuters, 2018, p. 311.
} 
autorizado (c), em que pese toda a discussão estabelecida no Superior Tribunal de Justiça (STJ). Cabe-nos, portanto, verificar a presença dos requisitos acima consignados ao caso em tela para que ocorra a aplicação das consequências decorrentes do lucro da intervenção.

Quanto a questão relativa à propriedade do bem (a), tal discussão apenas faz sentido se, como já asseverado anteriormente, quem exerce a posse direta não é o proprietário total do bem $^{15}$. Assim para que a presente análise tenha algum sentido é indispensável que se esteja diante de uma situação de copropriedade do bem utilizado exclusivamente pelo cônjuge ou companheiro, o que, normalmente, será aferido segundo os parâmetros do regime de bens estabelecido naquele casamento ou união estável que findou ${ }^{16}$.

Não se olvide que conforme consignado na lei, salvo disposição em contrário, normalmente estabelecida em sede de pacto antenupcial ${ }^{17}$, determinação legal expressa (art. 1.641 do Código Civil) ou no próprio corpo do contrato, que são situações manifestamente excepcionais, os bens adquiridos na constância do casamento, salvo as exceções legais, comunicam-se entre os cônjuges/companheiros, que se tornam meeiros deles, ou seja, proprietários de metade de tais bens, o que já deixa presumidamente definido qual o percentual do bem que pertence a cada um.

O segundo ponto a ser aferido está atrelado ao exercício da posse direta sobre o bem (b), o que também não se mostra de complexidade elevada, ainda mais em sede de término de relacionamento afetivo, vez que o mais usual é que a consequência imediata de tal rompimento seja a saída de um dos cônjuges/companheiros do lar conjugal, sendo a exceção a hipótese em que se mantem o convívio sob o mesmo teto após a separação de fato.

De qualquer sorte tal requisito de natureza fática é elemento de fácil comprovação, não exigindo uma atividade probatória de excelência para a sua verificação, já que no mais das vezes é fato incontroverso e aferido com provas testemunhais.

Surge, por fim, o requisito atrelado à existência ou não de autorização para o exercício exclusivo da posse (c). Considerando a situação sob análise se mostra bastante coerente entender-se pela ausência de uma autorização para a utilização total ou parcial de bem de outrem, de forma gratuita, quando há a ruptura de um relacionamento, ainda mais quando essa se dá de forma conflituosa. A presunção de existência de um negócio jurídico gratuito em tais circunstâncias não se mostra como a situação mais usual que possa permitir que se conclua por ela.

Acrescente-se ainda que não parece crível que quem reclama da utilização exclusiva de bem comum tenha conscientemente autorizado a utilização gratuita do bem, tampouco que se possa pensar na existência de uma autorização tácita. Se existe um permissivo para a utilização gratuita do bem esse haverá de ser substancialmente comprovado, sob pena de concluir-se pela

15 Evidente que a solução seria a mesma caso a propriedade fosse de apenas um dos cônjuges/companheiros e outro estivesse exercendo a posse sobre o bem sozinho, caso esse que a aplicação da obrigação de restituir ante ao lucro da intervenção se mostra ainda mais clara, contudo, o objetivo do presente texto está exatamente em tratar da hipótese de bem comum do casal

${ }^{16}$ Não se olvida a possibilidade de que a copropriedade decorra de negócio jurídico em que as partes tenham atuado com o objetivo de adquirir a propriedade do bem em condomínio, contudo tal hipótese é uma exceção em situações como as que busca tratar o presente texto.

17 Não é da cultura brasileira a realização de pactos antenupciais. 
ausência de qualquer concessão por parte do proprietário para a utilização do bem, caracterizando-se como uma modalidade de posse precária que, como tal, não se convalida pelo mero decurso do tempo.

Evidentemente que a questão que aqui se coloca está afeita a bens imóveis ou até mesmo móveis valor considerável, contudo não afastamos a presente discussão quanto a bens de pequeno valor.

Questão que ensejou grande celeuma quando da apreciação do dever de indenizar decorrente do condomínio (art. 1.319 do Código Civil) no Superior Tribunal de Justiça (STJ) residia no momento em que se tornava devido o dever de pagar os aluguéis decorrente da utilização de bem de outrem. O termo inicial, discutia-se, poderia ser a separação de fato, a separação judicial ou o divórcio, ou o momento da citação que ternaria incontroverso o interesse daquele que não tinha o bem consigo, a determinação da partilha, ou o pedido de dissolução do condomínio. Tal questão quando da utilização do conceito adequado se mostra irrelevante, vez que em sede de lucro da intervenção o que será aferido é qual o instante em que passou a ocorrer a utilização do bem alheio sem a devida autorização, tornando desnecessária a preocupação que se fez presente nos acórdãos analisados.

Assim, presentes os requisitos aqui considerados nos parece evidente a imposição das consequências do lucro da intervenção, com a determinação de que aquele que obteve benefícios ante a utilização de bens ou direitos alheios reverta tais ganhos (acréscimos ou montante que deixou de dispender) em favor do proprietário que se viu prejudicado, sendo certo que no caso em análise, caberá ao possuidor direto do bem que não lhe pertence integralmente o dever de entregar ao dono do bem o equivalente ao indevidamente obtido.

Dessa forma, se o cônjuge ou companheiro usou exclusivamente bem pertencente parcialmente àquele de quem se separou, haverá de pagar o valor equivalente ao aluguel do bem, que pode ser aferido mediante perícia, na proporção da extensão da sua posse precária.

\section{CONCLUSÃO}

O término do casamento ou da união estável é uma realidade cada vez mais constante nos dias atuais, sendo que tal fato dá azo à ocorrência de uma situação bastante corriqueira que é a do uso exclusivo de bem comum por parte de um dos cônjuges ou companheiros.

Tal situação revela-se como um manifesto caso de enriquecimento sem causa no qual uma pessoa aufere um benefício ante a utilização de bem alheio sem autorização para tanto, experimentando um ganho às custas de outrem, situação que se insere perfeitamente no conceito do lucro da intervenção.

O fato aqui descrito já foi levado à apreciação do Superior Tribunal de Justiça (STJ) contudo o tema apenas foi considerado sob a perspectiva da manutenção ou não da mancomunhão após a separação de fato ou divórcio, ou então sob a perspectiva do condomínio simples.

Todavia entendemos que face às características inerentes ao rompimento de tais 
modalidades de relacionamentos afetivos a discussão da permanência da comunhão decorrente do casamento não é a solução mais adequada, podendo o mesmo ser dito acerca da aplicação do art. 1.319 do Código Civil que trata de dano causado ao outro condômino.

Com a separação de fato não há mais que se falar em reflexos patrimoniais do casamento ou da união estável, vez que a comunhão de vidas que dá lastro a tal entendimento já não mais se faz presente. De outro lado, a figura do condomínio geral não se adequa da melhor forma às idiossincrasias inerentes dessa modalidade tão específica de copropriedade, considerando-se que mesmo sem uma manifestação expressa é patente que a separação de fato é elemento caracterizador do término da affectio que originou a situação de propriedade comum existente entre ambos.

A solução adequada à situação de uso exclusivo de bem comum, decorrente do fim relacionamento, é a da restituição do lucro da intervenção, havendo apenas de aferir a quem efetivamente pertence o referido bem, quem exerce a posse direta sobre ele e se há autorização para tanto. Assim, caso o bem seja alheio (ainda que parcialmente) e haja o exercício exclusivo da posse sem a devida autorização (que há de ser expressa), haverá o possuidor direto que ofertar ao proprietário o equivalente ao que não teve que dispender por tal uso, pagando o aluguel proporcional à parte do outro, desde o momento em que tal posse exclusiva teve início.

\section{REFERÊNCIAS}

CUNHA, Leandro Reinaldo da. Para além dos sonegados. O lucro da intervenção em caso de não colação. Migalhas, 29 set. 2020. Disponível em: https://migalhas.uol.com.br/coluna/migalhas-deresponsabilidade-civil/334014/para-alem-dos-sonegados--o-lucro-da-intervencao-em-caso-denao-colacao. Acesso em 27. jan. 2021.

FAJNGOLD, Leonardo; SALGADO, Bernardo; GUERRCHON, Dan. Lucro da intervenção: a disciplina e os julgamentos pioneiros no Superior Tribunal de Justiça. Revista Brasileira de Direito Civil - RBDCivil, Belo Horizonte, v. 21, jul./set. 2019

FARIAS, Cristiano Chaves de. ROSENVALD, Nelson. Curso de direito civil: Famílias. 7. ed., São Paulo: Atlas, 2015

GOMES, Josiane Araújo. Temas contemporâneos de direito das famílias. Volume 3. São Paulo: Editora Pillares, 2018.

GOMES, Orlando. Direitos Reais. 19. ed. rev. e atual. Rio de Janeiro: Forense, 2007.

KONDER, Carlos Nelson. Dificuldades de uma abordagem unitária do lucro da intervenção. Revista de Direito Civil Contemporâneo, v. 13, n. 4, p. 231-248, out./dez. 2017.

LÔBO, Paulo. Famílias. 2. ed., São Paulo: Saraiva, 2009.

SCHREIBER, Anderson. SILVA, Rodrigo da Guia. Aspectos relevantes para a sistematização do lucro da intervenção no direito brasileiro. Pensar, Fortaleza, v. 23, n. 4, p. 1-15, out./dez. 2018.

SILVA, Rodrigo da Guia. Enriquecimento sem causa: as obrigações restitutórias no direito civil. São Paulo: Thomson Reuters, 2018.

TEPEDINO, Gustavo; TEIXEIRA, Ana Carolina Brochado. Direito de Família. Rio de Janeiro: Forense, 2020. 
Recebido: 08.02.2021

Aprovado: 19.03 .2021

Como citar: CUNHA, Leandro Reinaldo da. Lucro da intervenção e o uso exclusivo do imóvel do casal após a separação de fato. Revista IBERC, Belo Horizonte, v. 4, n. 1, p. 52-64, jan./abr. 2021.

\section{(c) $(1) \circledast$}

